\title{
Subclinical Form of the American Visceral Leishmaniasis
}

\author{
Mônica Elinor Alves Gama/ ${ }^{+}$, Jackson Maurício Lopes Costa*, \\ Cláudia Maria Castro Gomes**, Carlos Eduardo Pereira Corbett**
}

Departamento de Medicina III (Pediatria) *Departamento de Patologia, Universidade Federal do Maranhão, Praça Gonçalves
Dias 21 ILA, 65020-270 São Luis, MA, Brasil **Departamento de Patologia, Universidade de São Paulo, São Paulo, Brasil

The subclinical form of visceral leishmaniasis (VL) shows nonspecific clinical manifestations, with difficulties being frequently met in its clinical characterization and diagnostic confirmation. Thus, the objective of the present study was to define the clinical-laboratory profile of this clinical form. A cohort study was conducted in the state of Maranhão, Brazil, from January/1998 to December/2000, with monthly follow-up of 784 children aged 0-5 years. Based on the clinical-laboratory parameters reported in the literature, four categories were established, with the children being classified (according to their clinical-evolutive behavior) as asymptomatic $(N=144)$ ), as having the subclinical form $(N=33)$ or the acute form $(N=12)$ or as subjects "without VL" $(N=595)$. Multiple discriminant analysis demonstrated that the combination of fever, hepatomegaly, hyperglobulinemia, and increased blood sedimentation rate (BSR) can predict the subclinical form of $V L$ as long as it is not associated with splenomegaly or leukopenia. Subjects with the subclinical form did not show prolonged or intermittent evolution or progression to the acute form of $V L$. Subclinical cases have a profile differing from the remaining clinical forms of $V L$, being best characterized by the combination of fever, hepatomegaly, hyperglobulinemia, and increased BSR.

Key words: visceral leishmaniasis - subclinical form - oligosymptomatic form

American visceral leishmaniasis (AVL) is a parasitic infection caused by Leishmania L. chagasi, endemic in many areas at Brazil, including the state of Maranhão. Clinically, AVL can be classified as asymptomatic (just infection), subclinical (or oligosymptomatic form), acute and, classic forms, which sometimes can present evolutionary behavior. These denominations and the characteristics described for each clinical form have been modified over the years, interfering with the evaluation of the incidence and clinical presentation mainly of the subclinical form because some authors use the terms "infection" and "subclinical" as synonyms (Pampiglione et al. 1974, Guerra et al. 1985, Evans et al. 1992, D’Oliveira Jr et al. 1997).

The study published by Badaró et al. (1986) has been adopted as a reference to characterize the subclinical form of AVL as nonspecific mild clinical manifestations lasting for more than 3 weeks, including fever, cough, diarrhea, malaise, mild hepatomegaly, and eventually splenomegaly with slight laboratory alterations, presenting a fluctuating course that evolves over a prolonged period of time (mean, 35 months). The authors showed that individuals with antibodies to Leishmania can be divided into four groups according to their clinical evolution: those who remain asymptomatic (23.2\%), those who develop the disease but without progression from the subclinical form $(17.4 \%)$, those with the subclinical form who progress to

Financial support: Fapesp, CNPq, Laboratório de Patologia de Moléstias Infecciosas/Universidade de São Paulo (LIM50)

${ }^{+}$Corresponding author. Fax number: +55- 98-227.0791. E-mail: mgama@elo.com.br

Received 8 June 2004

Accepted 12 November 2004 disease (15.1\%), and those with the subclinical form that is resolved after a prolonged period of time (44.2\%). In most cases, the children were initially indistinguishable.

Professionals working in endemic AVL areas often face doubts about children with nonspecific symptoms and about the evolution and clinical behavior of the subclinical form of AVL and its diagnostic confirmation. Doubts also arise about whether suitable therapy should be instituted since the determinant factors of the evolution to disease are not established and because of the confusion with others causes of mild symptoms. Thus, the objective of the present study was to define the clinical and laboratory profile of the subclinical form of AVL.

\section{PATIENTS AND METHODS}

A cohort study was carried out in endemic areas of AVL, in the state of Maranhão, Brazil, between January/ 1998 and Dececember/2000.

Areas of investigation - The areas selected were Vila Nova and Vila Bom Viver (villages in the municipal district of Raposa, MA, Brazil - Fig. 1) known to be endemic for AVL, with an incidence of 3.3 cases $/ 1000$ inhabitants per year. The district is located $28 \mathrm{~km}$ from the state capital, São Luis. The Center for Tropical Pathology and Social Medicine, Federal University of Maranhão (UFMA) and the National Health Foundation (Funasa, MA) have been conducting studies in this area for 15 years with the objective of controlling the more common diseases (AVL and malaria). Chagas disease, mansonic schistosomiasis or American tegumentary leishmaniasis have not been reported in this area (Caldas et al. 2001).

Study population - All 905 children aged 0-5 years, residents of Vila Nova and Vila Bom Viver, were assessed; however 784 children that respected regularly scheduled visits (every 45 days for 30 consecutive months) were studied. On the occasion of the first visit, ELISA using $L$. 


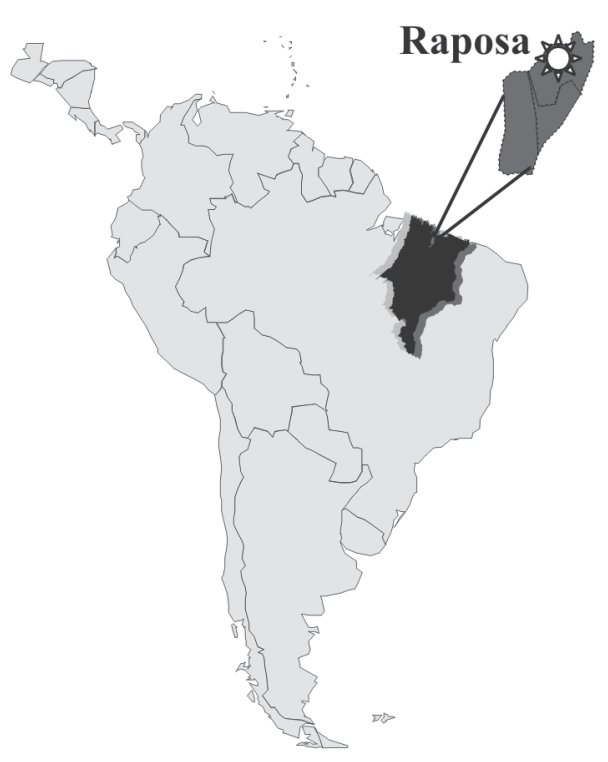

Fig. 1: municipal district of Raposa, in the São Luís Island, state of Maranhão, Brazil.

(L.) chagasi antigen was carried out to discriminate between individuals infected or not to Leishmania. Regardless of the serological results, all children were clinically evaluated and submitted to regular monthly visits for the possible detection of nonspecific symptoms. The health agent of Funasa/MA, and the community health agents of the municipal district helped to locate the children. If the children presented any symptoms, the adults responsible for them and the agents were instructed to return immediately for clinical evaluation and laboratory analysis (blood count, protein count, blood sedimentation rate, and transaminases determination). The children with symptoms were evaluated every 3 days until they could be classified and complementary exams were requested if necessary.

Children were assembled into four different groups according to the clinical and laboratory initial manifestation and to their final clinical course. The symptoms considered were fever, diarrhea, cough, pallor, hepatomegaly and/or splenomegaly. 1) AVL acute form/Group 1-12 children (classic symptoms of AVL); 2) asymptomatic form/ Group 2-144 children (positive ELISA), oligosymptomatic or subclinical; 3) form/Group 3-33 children (two or more mild symptoms, with positive ELISA); and 4) children with- out AVL classification/Group 4-595 children (specific clinical situation, not classified as a clinical form of AVL). After the children were classified as oligosymptomatic or as having the acute form of the disease, specific tests for the diagnosis of AVL were done - ELISA with leishmanial antigen, again, and a bone marrow aspirate to search for Leishmania amastigotes forms. A single pediatrician performed all clinical evaluations.

The clinical data were recorded and analyzed utilizing the SPSS-PC program (Statistical Package for Social Sciences, PC version 10.0). First, the incidence of the all variables [fever, cough, diarrhea, pallor, hepatomegaly, splenomegaly, leukopenia, lymphocytosis, anemia, thrombocytopenia, hypoalbuminemia, hyperglobulinemia, increased blood sedimentation rate (BSR) and transaminases] was calculated for each group and compared among groups using analysis of variance (ANOVA) or the KruskalWallis test. A multiple discriminant analysis was performed to identify the combination of variables that would permit the discrimination between groups.

The study was approved by the Ethics Committees of the University of São Paulo and the Federal University of Maranhão and fulfilled the requirements of the Resolution of the National Council for Health 196/96 for research involving humans.

\section{RESULTS}

Fig. 2 shows the distribution of children into the four groups based on their final clinical course. After the children identification with positive or not ELISA (infected or not to Leishmania) it was proceeded its monthly followup. Along the clinical reevaluations, it was observed that 12 children who had developed to AVL acute form out of 4 presented positive ELISA previously and from 33 children classified with subclinical form only 8 of them presented an infection in the serum conspicuosness observed previously to the classification.

The incidence of the variables was calculated for each group and a comparative analysis of the data by ANOVA or the Kruskal-Wallis test showed that all variables differed significantly among the 4 groups, except cough $(\mathrm{p}=$ 0.630 ).

A multiple discriminant analysis (MDA) was performed to determine the combination of variables that characterized the subclinical form. Two functions were derived to distinguish the oligosymptomatic group from the others (Table I). The importance of each variable within each function is expressed by its correlation coefficient and its importance for the diagnosis of the subclinical form was

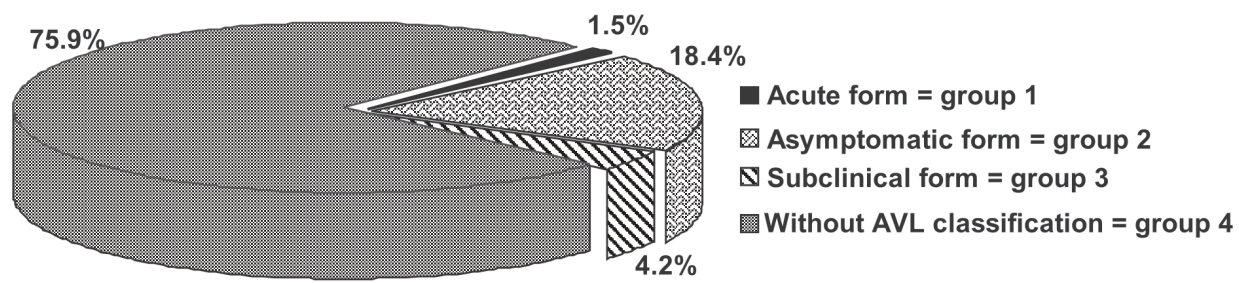

Fig. 2: percent distribution of the 784 children according to the final clinical classification. 
TABLE I

Rotated structure matrix correlation between the discriminant variables and the discriminant functions (variables ordered by size of correlation within the function)

\begin{tabular}{|c|c|c|}
\hline \multirow[b]{2}{*}{ Variables } & \multicolumn{2}{|c|}{ Functions } \\
\hline & 1 & 2 \\
\hline Hyperglobulinemia & $0.691^{b}$ & 0.078 \\
\hline Hepatomegaly & $0.412^{b}$ & 0.125 \\
\hline Increased blood sedimentation rate & $0.311^{b}$ & -0.008 \\
\hline Fever & $0.087^{b}$ & -0.007 \\
\hline Pallor ${ }^{a}$ & $0.079^{b}$ & 0.023 \\
\hline Diarrhea $^{a}$ & $0.068^{b}$ & -0.036 \\
\hline Leukopenia & -0108 & $0.871^{b}$ \\
\hline Splenomegaly & 0.159 & $0.232^{b}$ \\
\hline Increased transaminases & 0.270 & -0121 \\
\hline Thrombocytopenia & -0.059 & 0.224 \\
\hline Hypoalbuminemia & -0.054 & 0.197 \\
\hline Lymphocytosis & 0.131 & 0.029 \\
\hline Anemia ${ }^{a}$ & 0.080 & 0.044 \\
\hline Cough $^{a}$ & 0.006 & 0.005 \\
\hline
\end{tabular}

$a$ : variable not used in the analysis (with no significant contribution to the statistical model); $b$ : absolute correlation between each variable and discriminant function.

compared with the other groups. To validate the multiple discriminant models, its functions were applied to the validation sample - these can represented $99.9 \%$ of the variations of the original measurement. Cross-validation showed that the model correctly classified $82 \%$ of the all cases.

The combination of fever, hepatomegaly, hyperglobulinemia, and increased BSR (function 1) distinguished the subclinical form from the asymptomatic cases and from children without AVL classification. MDA also showed that the combination of splenomegaly and leukopenia (function 2) distinguished the acute form from the subclinical cases. Therefore, when function 1 values are high, the subclinical form is more likely to be present, and when function 2 values are high, the acute form is more likely to be present. Fig. 3 shows the difficulty in dividing group 2 (asymptomatic) and group 4 (without AVL classification) into different clinical forms. The other variables contributed little to the statistical model.

For the subclinical form, the clinical and laboratory findings were variable and fever was the major complaint (Table II). The duration of symptoms ranged from 10 to 40 days, with no intermittent course during follow-up. It is considered hepatomegaly and splenomegaly when the guts were felt below the flange joint in the back, and it was observed that the hepatomegaly varied from 3 to 5 $\mathrm{cm}$, and the splenomegaly from 3 to $5 \mathrm{~cm}$, however they were not present at all children. The associations of signs and symptoms were varied (Table III). By the way, in the group with the acute form, there was always an association of four signs/symptoms - fever, hepatomegaly, splenomegaly, and pallor - in each individual.

Table IV shows the clinical and laboratory differences between the oligosymptomatic cases with a negative or positive search of Leishmania in the bone marrow aspirate. The duration of symptoms and the dimensions of the visceromegalies did not differ between the two groups (p\# 0.05).

\section{DISCUSSION}

No previous studies have been performed with monthly follow-up of children infected and not to Leishmania to discriminate between the subclinical or oligosymptomatic cases from the other frequent and possible diagnoses.

The present study confirmed that the oligosymptomatic form was more frequent than the acute form of AVL. However, in the literature, the subclinical form occurs in almost $60 \%$ of the infected subjects (Badaró et al. 1986) while in the present study it occurred in only $17.4 \%$, probably because the other common causes of the mild symptomatology were evaluated and ruled out before the AVL classification. This means that, in an endemic area, the professionals must consider other usual diagnoses even in the presence of a reactive serological test.

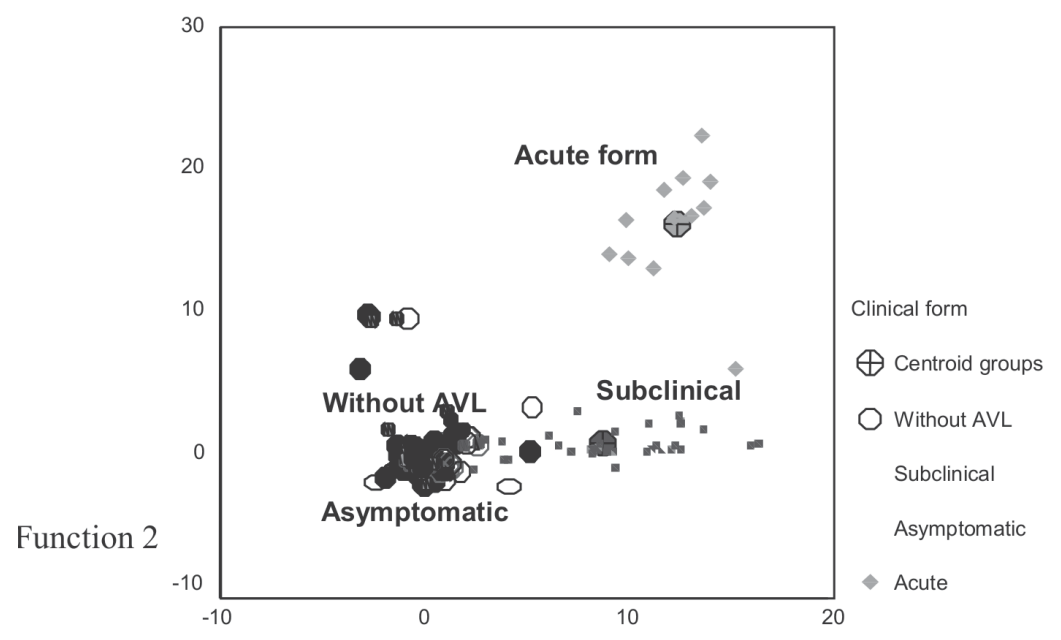

Function 1

Fig. 3: distribution of the 784 children by clinical form according to the discriminant functions. 
The subclinical cases (all children aged 5 years or less) did not progress to the acute form of AVL. In the study by Badaró et al. (1986) the mean age of the subclinical group progressing to disease was four years and the mean age

\section{TABLE II}

Distribution of the clinical and laboratory findings for the 33 children classified with the oligosymptomatic form

\begin{tabular}{|c|c|c|c|}
\hline & & Frequency & Percentage \\
\hline \multirow[t]{2}{*}{ Fever } & Yes & 33 & 100 \\
\hline & No & - & - \\
\hline \multirow[t]{2}{*}{ Diarrhea } & Yes & 8 & 24.2 \\
\hline & No & 25 & 75.8 \\
\hline \multirow[t]{2}{*}{ Cough } & Yes & 1 & 3 \\
\hline & No & 32 & 97 \\
\hline \multirow[t]{2}{*}{ Pallor } & Slight & 11 & 33.3 \\
\hline & Middle & 1 & 3 \\
\hline \multirow[t]{2}{*}{ Hepatomegaly } & Yes & 17 & 51.5 \\
\hline & No & 16 & 48.5 \\
\hline \multirow[t]{2}{*}{ Splenomegaly } & Yes & 10 & 30.3 \\
\hline & No & 23 & 69.7 \\
\hline \multirow[t]{2}{*}{ Anemia } & Yes & 24 & 72.8 \\
\hline & No & 9 & 27.3 \\
\hline \multirow[t]{2}{*}{ Leukopenia } & Yes & - & - \\
\hline & No & 33 & 100 \\
\hline \multirow[t]{2}{*}{ Lymphocytosis } & Yes & 20 & 60.6 \\
\hline & No & 13 & 39.4 \\
\hline \multirow[t]{2}{*}{ Thrombocytopenia } & Yes & - & - \\
\hline & No & 33 & 100 \\
\hline \multirow[t]{2}{*}{ Hypoalbuminemia } & Yes & - & - \\
\hline & No & 33 & 100 \\
\hline \multirow[t]{2}{*}{ Hyperglobulinemia } & Yes & 21 & 63.6 \\
\hline & No & 12 & 36.4 \\
\hline \multirow[t]{2}{*}{ Increased HSV } & Yes & 29 & 87.9 \\
\hline & No & 4 & 12.1 \\
\hline \multirow[t]{2}{*}{ Bone marrow aspirate } & Positive & 12 & 36.4 \\
\hline & Negative & 13 & 39.4 \\
\hline
\end{tabular}

TABLE III

Associations of signs/symptoms observed in the 33 oligosymptomatics cases

\begin{tabular}{lcc}
\hline & \multicolumn{2}{c}{ Oligosymptomatic cases } \\
\cline { 2 - 3 } Clinical associations & $\mathrm{Nr}$ & $\%$ \\
\hline Fever associated with: & 9 & \\
Hepatomegaly & 5 & 27.3 \\
Pallor & 4 & 15.1 \\
Splenomegaly & 3 & 12.1 \\
Diarrhea + pallor & 2 & 9.1 \\
Hepatomegaly + splenomegaly & 2 & 6.1 \\
Diarrhea & 2 & 6.1 \\
Hepatomegaly + splenomegaly + pallor & 2 & 6.1 \\
Hepatomegaly + pallor & 2 & 6.1 \\
Hepatomegaly + diarrhea & 1 & 6.1 \\
Splenomegaly + cough & 3 \\
Splenomegaly + diarrhea & 1 & 3 \\
\hline
\end{tabular}

of the subclinical group with spontaneous resolution was 8 years.

In this cohort, prolonged or intermittent mild illness was not observed, in agreement with Evans et al. (1992), who followed-up the infected subjects, although there are literature reports showing that the duration of symptoms is up to 35 months in the subclinical form (Badaró et al. 1986). Different epidemiological situations can determine different clinical behavior.

The spontaneous resolution of the subclinical form without progression to the acute form has been discussed since 1906, although many authors refer to the asymptomatic form as being synonymous of the subclinical form, a fact that impairs comparative analysis (Leishman 1906 apud Pampiglione 1974, Guerra et al. 1985, Holaday et al. 1993, Shiddo et al. 1995, D’ Oliveira Jr et al. 1997)

Using the multiple discriminant analysis, the interaction of the all variables was determined to define the subclinical form profile. It showed that two associations (functions 1 and 2) represented almost $100 \%$ of the cases. The combination of fever, hepatomegaly, hyperglobulinemia, and increased BSR (function 1) can predict the oligosymptomatic form, and therefore this function can be interpreted as "nonspecific clinical and laboratory manifestations related to AVL". The occurrence of splenomegaly and leukopenia (function 2) distinguished the acute form from the oligosymptomatic form and can therefore be interpreted as "specific manifestation of AVL disease" because it characterize the illness, occurring in almost $100 \%$ of the cases of acute form of AVL (Silva 1957, Pastorino 1993, WHO 1997).

On the basis of these findings, in the present analysis the subclinical form was characterized as a peculiar and specific clinical form which differs from the other diagnoses with mild symptomatology and which is not an early stage of AVL disease (acute or classic forms).

\section{TABLE IV}

Clinical-laboratory characteristics of the 33 oligosymptomatics cases according to bone marrow positivity (12 positive cases and 13 negative cases)

\begin{tabular}{lccc}
\hline & \multicolumn{3}{c}{ Search for Leishmania } \\
\cline { 2 - 4 } & Positive & Negative & $\mathrm{NP}$ \\
Clinical-laboratory findings & $\mathrm{Nr}$ & $\mathrm{Nr}$ & $\mathrm{Nr}$ \\
\hline Fever associated with: & 2 & 3 & \\
Hepatomegaly & 2 & 2 & 1 \\
Pallor & - & 2 & 2 \\
Splenomegaly & - & 3 & - \\
Diarrhea + pallor & 1 & 1 & - \\
Hepatomegaly + splenomegaly & 1 & - & 1 \\
Diarrhea & 2 & - & - \\
Hepatosplenomegaly + pallor & 1 & 1 & - \\
Hepatomegaly + pallor & 1 & 1 & - \\
Hepatomegaly + diarrhea & 1 & - & - \\
Splenomegaly + cough & 1 & - & - \\
Splenomegaly + diarrhea & 12 & 13 & 8 \\
\hline Total & & & \\
\hline NP: not performed & & & \\
\hline
\end{tabular}

NP: not performed 
It is important to observe the overlap of the groups of asymptomatic subjects and of subjects "without AVL" which emphasizes that, without a suggestive symptomatology, a positive search of anti-Leishmania antibodies does not indicate a parasitological investigation or specific treatment. In spite of the peculiar profile, in the oligosymptomatic form the bone marrow aspirate did not contribute to the characterization of the disease and thus would not be essential in daily practice.

In the present study, the symptomatology was variable but the literature also reports many variations. Pampiglione et al. (1974) reported infected children with discrete splenomegaly and hyperglobulinemia; Ho et al. (1982) reported 34 cases with splenomegaly ( 12 with associated fever and malaise). In a transverse study, Shiddo et al. (1995) reported 7 children infected to Leishmania with splenomegaly (two with diarrhea and cough). In the study performed in Jacobina/Bahia, the subclinical group with spontaneous resolution presented diarrhea (18.4\%), cough $(13.1 \%)$, fever $(10.5 \%)$, hepatomegaly $(97.4 \%)$, and splenomegaly (28.9\%), with $27.3 \%$ of positivity in the bone marrow aspirate - some cases with leukopenia too (Badaró et al. 1986). These data are divergent, probably due to the different study models.

This study demonstrated that there was a wide diversity of the symptoms associated with the oligosymptomatic form, but the model of analysis proposed showed that, although mild and nonspecific, the clinical manifestations were of significant value to define the oligosymptomatic or subclinical form of AVL.

During the clinical analysis, the immunological markers for the oligosymptomatic or subclinical form of VL were identifying. This can be seen in Gama et al. (2004).

\section{ACKNOWLEDGMENT}

To the health agent of Funasa/MA and the community health agents of the municipal district of Raposa/MA for their work with the children and their families.

\section{REFERENCES}

Badaró R, Jones T, Carvalho E, Sampaio D, Reed S, Barral A, Teixeira R, Johnson Jr W 1986. New perspectives on a subclinical form of visceral leishmaniasis. J Infect Dis 154: 1003-1011.

Caldas A, Silva D, Pereira C, Costa J 2001. Infecção por
Leishmania (Leishmania) chagasi em crianças de uma área endêmica de leishmaniose visceral americana, na Ilha de São Luís, Maranhão, Brasil. Rev Soc Bras Med Trop 34: 445451.

D’Oliveira Jr A, Costa S, Barbosa A, Orge M, Carvalho E 1997. Asymptomatic Leishmania chagasi infection in relatives and neighbors of patients with visceral leishmaniasis. Mem Inst Oswaldo Cruz 92: 15-20.

Evans T, Teixeira M, MCauliffe I, Vasconcelos A, Sousa A, Lima J, Pearson R 1992. Epidemiology of visceral leishmaniasis in northeast Brazil. J Infect Dis 166: 1124-1132.

Gama MEA, Costa, JML, Pereira, JCR, Gomes, CMC, Corbett, CEP 2004. Serum cytokine profile in the subclinical form of visceral leishmaniasis. Braz J Med Biol Res 37: 129-36

Guerra M, Furtado T, Barros G, Sessa P, Daher V 1985. Infecção subclínica na leishmaniose tegumentar. An Bras Dermatol 60: 365-369.

Ho M, Siongok K, Lyerly W, Smith D 1982. Prevalence and disease spectrum in a new focus of visceral leishmaniasis in Kenya. Trans R Soc Trop Med Hyg 76: 741-746.

Holaday B, Pompeu M, Evans T, Braga D, Teixeira M, Sousa A, Sadick M, Vasconcelos A, Abrams J, Pearson R, Locksley R 1993. Correlates of Leishmania-specific immunity in the clinical spectrum of infection with Leishmania chagasi. $J$ Infect Dis 167: 411-417.

Leishman WB 1906. Handbuch der Tropenkrankheiten, 2nd ed., Leipzig apud Pampiglione S, Manson-Bahr P, Giungi F, Giunti G, Parenti A, Troti G 1974. Studies on Mediterranean leishmaniasis II. Asymptomatic cases of visceral leishmaniasis. Trans R Soc Trop Med Hyg 68: 349-358.

Pampiglione S, Manson-Bahr P, Giungi F, Giunti G, Parenti A, Troti G 1974. Studies on Mediterranean leishmaniasis II. Asymptomatic cases of visceral leishmaniasis. Trans $R$ Soc Trop Med Hyg 68: 349-358.

Pastorino A 1993. Contribuição para o Estudo da Leishmaniose Visceral na Infância: Aspectos Clínico-laboratoriais de 78 casos, MSc Thesis, Universidade de São Paulo, São Paulo, $100 \mathrm{pp}$.

Shiddo S, Mohamed A, Akuffo H, Mohamud K, Herzi A, Mohamed H, Huldt G, Nilsson L, Ouchterlony A, Thorstensson R 1995. Visceral leishmaniasis in Somalia: prevalence of markers of infection and disease manifestations in a village in an endemic area. Trans $R$ Soc Trop Med Hyg 89: 361-365.

Silva J 1957. Leishmaniose visceral (calazar), Thesis, Serviço Nacional de Educação Sanitária, Rio de Janeiro, 498 pp.

WHO-World Health Organization 1997. Manual de Controle da Leishmaniose Visceral, Organização Pan-Americana, Geneve, 89 pp. 
